\title{
PENGARUH KUALITAS INFORMASI DAN KEMUDAHAN TRANSAKSI TERHADAP KEPUASAN KONSUMEN SERTA DAMPAKNYA PADA LOYALITAS KONSUMEN DALAM BERBELANJA FASHION ONLINE DI BANDA ACEH
}

\author{
Safrika', Rahman Lubis', Sofyan Idris' \\ Magister Manajemen Program Pascasarjana Universitas Syiah Kuala Banda Aceh \\ Fakultas Ekonomi dan Bisnis Universitas Syiah Kuala Banda Aceh
}

\begin{abstract}
This research aims to effects the influence of the quality of information and ease of discounted rates on consumer satisfaction and its impact on customer loyalty in shopping online fashion products in Banda Aceh. Research samples as much as 120 people of Banda Aceh which is consumers who never shop online. The collection of data using questionnaires and then analyzed with data using statistics structural equition equipment models (SEM) with this method of Partial Square (PLS). Studies have found that the quality of information and ease of discounted rates affect customer satisfaction and loyalty in shopping fashion online in Banda Aceh. Consumer satisfaction affect customer loyalty. Quality of information and ease of discounted rates affect customer loyalty in shopping fashion online in Banda Aceh through consumer satisfaction. The influence of the direct effect) both variables to customer loyalty was considered significant. Then the influence of the direct effect of consumer satisfaction toward consumer loyality is also significant. Thus it can be concluded that consumer satisfaction can serve as an intermediary variable (intervening variables) between consumer satisfaction in one side with the quality of information and ease of discounted rates on the other side
\end{abstract}

Key Words : Loyalits Consumers, consumer satisfaction, quality of information and ease of transaction.

\begin{abstract}
ABSTRAK
Penelitian ini bertujuan untuk menganalisis pengaruh kualitas informasi dan kemudahan transaksi terhadap kepuasan konsumen serta dampaknya pada loyalitas konsumen dalam berbelanja produk fashion online di Banda Aceh. Sampel penelitian sebanyak 120 masyarakat Banda Aceh yang merupakan konsumen yang pernah berbelanja online. Pengumpulan data menggunakan kuesioner dan selanjutnya data dianalisis dengan menggunakan peralatan statistik structural equition model (SEM) dengan metode Partial Least Square (PLS). Penelitian menemukan bahwa kualitas informasi dan kemudahan transaksi berpengaruh terhadap kepuasan konsumen dan loyalitas konsumen dalam berbelanja fashion online di Banda Aceh. Kepuasan konsumen berpengaruh terhadap loyalitas konsumen. Kualitas informasi dan kemudahan transaksi berpengaruh terhadap loyalitas konsumen dalam berbelanja fashion online di Banda Aceh melalui kepuasan konsumen. Pengaruh langsung (direct effect) kedua variabel tersebut terhadap loyalitas konsumen dinilai signifikan. Selanjutnya pengaruh langsung (direct effect) kepuasan konsumen terhadap loyalitas konsumen juga signifikan. Dengan demikian dapat disimpulkan bahwa kepuasan konsumen dapat berperan sebagai variabel perantara (intervening variabel) antara kepuasan konsumen di satu sisi dengan kualitas informasi dan kemudahan transaksi di sisi lain
\end{abstract}

Kata Kunci : Loyalits Konsumen, Kepuasan Konsumen, Kualitas Informasi dan Kemudahan Transaksi.

\section{Latar Belakang Masalah}

E-commerce adalah suatu jenis dari mekanisme bisnis secara elektronis yang memfokuskan diri pada transaksi bisnis berbasis individu dengan menggunakan internet sebagai medium pertukaran barang atau jasa baik antara dua buah institusi maupun antara institusi dan konsumen langsung. Dalam e-commerce vendor berhubungan langsung dengan konsumen melalui website yang sudah dibangun untuk menyajikan produk virtual yang tidak bisa disentuh oleh konsumen secara langsung.

Dunia fashion belakangan ini semakin berkembang pesat. Fashion menjadi magnet penarik bagi pembeli online baik konsumen yang berjenis kelamin laki-laki maupun perempuan yang ingin berbelanja lewat dunia maya untuk pertama kalinya. Konsumen yang 
punya akses internet lebih mepertimbangkan untuk membeli pakaian meliputi berbagai aksesorisnya.

Terdapat banyak faktor yang menyebabkan seseorang untuk berbelanja online di situs Internet dan bersikap loyal dalam berbelanja. Mulai dari kualitas informasi produk yang ditawarkan jelas, kepercayaan konsumen kepada perusahaan, fasilitas kemudahan transaksi dan kepuasan konsumen setelah menerima dan melihat kualitas jenis barang, sampai dengan beberapa faktor lainnya.

Suatu perusahaan yang menerapkan ecommerce tidak hanya memperhatikan dari penerapan e-commerce nya, namun sangat perlu memperhatikan kualitas informasi dari perusahaan itu sendiri, karena kualitas informasi yang baik akan sangat menjadi pemicu kepuasan konsumen sehingga menciptakan konsumen yang loyal.

Perilaku konsumen yang menginginkan informasi cepat, transaksi yang dapat dilakukan selama 24 jam, dan meningkatnya jumlah pemakai internet yang naik secara drastis setiap tahunnya disinyalir menjadi faktor pendorong bagi berkembangnya online shopping. Kosumen lebih memilih berbelanja di perusahaan yang menawarkan kemudahan bertransaksi daripada perusahaan yang memiliki sederetan langkah persyaratan dalam melakukan transaksi. Kemudahan bertransaksi menjadi salah satu penyebab konsumen menjadi loyal.

Kepuasan pelanggan dan loyalitas merupakan elemen yang menentukan kesuksesan implementasi konsep pemasaran. Di dalam bisnis kepuasan pelanggan adalah hal yang penting. Kepuasan pelanggan merupakan sarana yang kuat untuk memprediksi customer retention (retensi pelanggan), customer loyalty (loyalitas pelanggan), dan product repurchase (pembelian kembali atas suatu produk) (Smith dan Albaum, 2010:60). Kepuasan pelanggan terjadi ketika customer expectation (harapan pelanggan) dapat dipenuhi oleh pihak pemberi layanan. Menurut Anderson dan Lehman (2011:80), pelayanan yang berkinerja tinggi adalah pelayanan yang mampu memuaskan kebutuhan pelanggan atau dengan kata lain mampu melebihi harapan dari pelanggan. Dengan kata lain, kepuasan terjadi ketika harapan sama dengan delivery (penyampaian) atau kenyataan yang diterima oleh konsumen.

\section{Perumusan Masalah}

1 Apakah kualitas informasi berpengaruh terhadap kepuasan konsumen dalam berbelanja fashion online di Banda Aceh?

2 Apakah Kemudahan transaksi berpengaruh terhadap kepuasan konsumen dalam berbelanja fashion online di Banda Aceh?

3 Apakah kualitas informasi berpengaruh terhadap loyalitas konsumen dalam berbelanja fashion online di Banda Aceh?

4 Apakah kemudahan trasnsaksi berpengaruh terhadap loyalitas konsumen dalam berbelanja fashion online di Banda Aceh?

5 Apakah kepuasan konsumen berpengaruh terhadap loyalitas konsumen dalam berbelanja fashion online di Banda Aceh?

6 Apakah kualitas informasi berpengaruh terhadap loyalitas konsumen melalui kepuasan konsumen dalam berbelanja fashion online di Banda Aceh?

7 Apakah kemudahan transaksi berpengaruh terhadap loyalitas konsumen melalui kepuasan konsumen dalam berbelanja fashion online di Banda Aceh?

\section{Tujuan Penelitian}

1 Untuk mengetahui pengaruh kualitas informasi terhadap kepuasan konsumen dalam berbelanja fashion online di Banda Aceh.

2 Untuk mengetahui pengaruh kemudahan transaksi terhadap kepuasan konsumen dalam berbelanja fashion online di Banda Aceh.

3 Untuk mengetahui pengaruh kualitas informasi terhadap loyalitas konsumen dalam berbelanja fashion online di Banda Aceh.

4 Untuk mengetahui pengaruh Kemudahan transaksi terhadap loyalitas konsumen dalam berbelanja fashion online di Banda Aceh?

5 Untuk mengetahui pengaruh Kepuasan Konsumen terhadap Loyalitas konsumen dalam berbelanja fashion online di Banda Aceh.

6 Untuk mengetahui pengaruh kualitas informasi terhadap loyalitas konsumen melalui kepuasan konsumen dalam berbelanja fashion online di Banda Aceh.

7 Untuk mengetahui pengaruh kemudahan transaksi terhadap loyalitas konsumen melalui kepuasan konsumen dalam berbelanja fashion online di Banda Aceh. 


\section{Manfaat Penelitian}

Manfaat Akademisi

Diharapkan dapat meningkatkan pemahaman tentang pengaruh kualitas informasi (information quality) dan kemudahan transaksi (ease of use) terhadap kepuasan konsumen dan dampaknya pada loyalitas konsumen dalam berbelanja fashion online.

\section{Manfaat Praktisi}

Hasil penelitian ini diharapkan dapat memberikan kontribusi praktis dan bermanfaat untuk usaha bisnis online dalam merumuskan strategi pemasaran mereka guna mempertahankan keunggulan kompetitif dan terus mengembangkan inovasi baru dari sistem situs online shoping di masa yang akan datang yang inovatif, murah, menarik, dan dapat dipercaya.

\section{TINJAUANPUSTAKA}

Loyalitas Konsumen (customer loyalty)

Menurut Shellyana dan Dharmmesta (2010: 72), loyalitas dapat diartikan sebagai pola pembelian ulang konsumen pada merek yang merupakan loyalitas sesungguhnya atau loyalitas pada merek tunggal. Loyalitas pelanggan merupakan manifestasi dan kelanjutan dari kepuasan konsumen walaupun tidak mutlak merupakan hasil kepuasan konsumen.

Pelanggan yang dianggap loyal akan berlangganan atau melakukan pembelian ulang selama jangka waktu tertentu. Pelanggan yang loyal sangat berarti bagi badan usaha karena biaya untuk mendapatkan pelanggan baru lebih mahal daripada memelihara pelanggan lama (Peter dan Olson, 2009: 45).

Kepuasan Konsumen (Customer Satisfaction)

Kepuasan pelanggan adalah persepsi pelanggan bahwa harapannya telah terpenuhi atau terlampaui (Gerson, 2010:3). Kepuasan pelanggan bermakna perbandingan antara apa yang diharapkan konsumen dengan apa yang dirasakan konsumen ketika menggunakan produk tersebut. Bila konsumen merasakan performa produk sama atau melebihi ekspektasinya, berarti mereka puas. Sebaliknya jika performa produk kurang dari ekspektasinya, berarti mereka tidak puas.

Kepuasan pelanggan dapat diketahui setelah pelanggan menggunakan produk atau jasa pelayanan. Kepuasan pelanggan merupakan evaluasi purna beli atau hasil evaluasi setelah membandingkan apa yang dirasakan dengan harapannya (R.kenneth Teas 2013: 78).
Kualitas Informasi (information quality)

Kualitas informasi mengandung banyak pengertian, menurut George H. Bodnar, (2009: 20) adalah kesesuaian tingkat baik buruknya suatu data yang diolah sehingga dapat dijadikan dasar untuk mengambil sebuah keputusan yang tepat. Kualitas informasi merupakan kualitas output yang berupa informasi yang dihasilkan oleh sistem informasi yang digunakan.

DeLone dan McLean (2010:98) mengemukakan hubungan antara kualitas informasi (information quality) dengan pengaruh individu (individual impact), mereka menemukan hubungan yang signifikan antara variabel tersebut. DeLone dan McLean mengukur kualitas informasi dengan accuracy, timeliness, completeness, relevance, dan consistency.

Kemudahan Transaksi

Kemudahan dalam penggunaan adalah salah satu hal yang menjadi pertimbangan bagi pembeli online, Perceived ease of use didefinisikan Davis et al., (2010:65) merupakan seberapa besar teknologi komputer dirasakan relatif mudah untuk dipahami dan digunakan. Faktor kemudahan ini terkait dengan bagaimana operasional bertransaksi secara online.

Kemudahan penggunaan dalam konteks ini bukan saja kemudahan untuk mempelajari dan menggunakan suatu sistem tetapi juga mengacu pada kemudahan dalam melakukan suatu pekerjaan atau tugas dimana pemakaian suatu sistem akan semakin memudahkan seseorang dalam bekerja dibanding mengerjakan secara manual.

\section{METODOLOGI PENELITIAN}

Tehnik Analisi Data

Seluruh tahap pengujian dalam penelitian menggunakan Evaluasi Goodness of Fit Model PLS berupa Outer Model dan Inner Model.

\section{HASIL PEMBAHASAN}

Variabel yang mempunyai rata-rata skor tertinggi adalah variabel kualitas informasi sebesar 4,344. Sedangkan variabel kepuasan konsumen merupakan variabel yang memiliki rata-rata skor terendah dibandingkan dengan skor rata-rata variabel kemudahan transaksi dan loyalitas konsumen yaitu 4,028. Dengan demikian kualitas informasi merupakan variabel yang sudah dinilai baik dalam penelitian. Indikator yang mempunyai rata-rata skor tertinggi pada variabel kualitas informasi adalah indikator kejelasan informasi sebesar 4,39. 
Kejelasan informasi diberikan nilai paling tinggi dan dinilai baik oleh responden, hal ini menunjukan dengan adanya informasi yang jelas dalam mempromosikan suatu produk berdasarkan detail produk akan lebih menarik minat konsumen untuk melihat dan memutuskan melakukan pembelian secara online.

\section{Convergent validity}

Convergent Validity dari model pengukuran dengan refleksif indikator dinilai berdasarkan korelasi antara item score atau component score yang diestimasi dengan Soflware PLS. Ukuran refleksif individual dikatakan tinggi jika berkorelasi lebih dari 0.70 dengan variabel yang diukur. Dalam penelitian ini akan digunakan batas loading factor sebesar 0.5 .

Nilai outer model atau korelasi antara variabel dengan variabel telah memenuhi convergent validity karena seluruh memiliki nilai loading factor di atas 0.50 .

\section{Discriminant Validity}

Discriminant validity dalam penelitian ini juga dapat diketahui dengan melihat nilai square root of averagevariance extracted (AVE). Nilai yang disarankan adalah di atas 0,5. Berikut adalah nilai AVE dalam penelitian ini:

\section{AVERAGE VARIANCE EXTRACTED} (AVE)

\begin{tabular}{|c|c|}
\hline & AVE \\
\hline KI (X1) & 0,577 \\
\hline KT (X2) & 0,618 \\
\hline KK $(Y)$ & 0,543 \\
\hline LK $(\mathrm{Z})$ & 0,585 \\
\hline
\end{tabular}

Tabel di atas memberikan nilai AVE di atas 0,5 untuk semua konstruk yang terdapat pada model penelitian. Nilai terendah AVE adalah sebesar 0,543 pada konstruk KK (Kepuasan Konsumen). Sehingga dapat disimpulkan data memiliki discriminant validity yang baik.

\section{Composite Reliability}

Kriteria validity dan reliabilitas juga dapat dilihat dari nilai reliabilitas suatu variabel dan nilai Average Variance Extracted (AVE) dari masing-masing variabel. Variabel dikatakan memiliki reliabilitas yang tinggi jika nilai composite reliablity diatas 0.70 dan AVE berada diatas 0.50. Pada Tabel 4.13 akan disajikan nilai Composite Reliability.

\begin{tabular}{|c|c|}
\hline Variabel & $\begin{array}{c}\text { Composite } \\
\text { Reliability }\end{array}$ \\
\hline Kualitas Informasi (X1) & 0,872 \\
\hline Kemudahan Transaksi (X2) & 0,866 \\
\hline Kepuasaan Konsumen (Y) & 0,856 \\
\hline Loyalitas Konsumen (Z) & 0,849 \\
\hline
\end{tabular}

Tabel di atas menginformasikan bahwa seluruh variabel memenuhi composite reliability karena nilainya diatas angka yang direkomendasikan, yaitu diatas 0.7 yangsudah memenuhi kreteria realibel.Berdasarkan dari hasil evaluasi secara keseluruhan, baik convergent. discriminant validity, composite reliability, yang telah dipaparkan diatas, maka dapat disimpulkan bahwa indicator-indikator sebagai pengukur variabel laten merupakan pengukur yang valid dan reliable.

\section{Pengujian Model Struktural (Inner Model)}

Penilaian model dengan PLS dimulai dengan melihat $\mathrm{R}$-square untuk setiap variabel laten dependen. Perubahan nilai R-square dapat digunakan untuk menilai pengaruh variabel laten eksogen tertentu terhadap variabel laten endogen. Tabel berikut memperlihatkan hasil estimasi R-square dengan menggunakan SmartPLS.

\begin{tabular}{|l|l|}
\multicolumn{2}{c}{ Nilai $R$-Square } \\
\begin{tabular}{|l|l|}
\hline Variabel & R-Square \\
\hline Kualitas Informasi (X1) & \\
\hline Kemudahan Transaksi (X2) & \\
\hline Kepuasaan Konsumen (Y) & 0,335 \\
\hline Loyalitas Konsumen (Z) & 0,782 \\
\hline
\end{tabular}
\end{tabular}

Pada tabel menunjukkan nilai R-square variabel kepuasan konsumen 0.335 dan loyalitas konsumen 0.782. Semakin tinggi nilai R-square, maka semakin besar kemampuan variabel eksogen tersebut dapat dijelaskan oleh variabel endogen sehingga semakin baik persaman struktural. 


\section{Pengujian Hipotesis}

Signifikansi parameter yang diestimasi memberikan informasi yang sangat berguna mengenai hubungan antara variabel-variabel penelitian. Dasar yang digunakan dalam menguji hipotesis adalah nilai yang terdapat pada output result for inner weight. Berdasarkan hasil pengujian baik hipotesis langsung maupun hipotesis mediasi yang ada dalam hipotesis penelitian ini dinyatakan diterima.

\section{KESIMPULAN \& SARAN}

\section{Kesimpulan}

1 Kualitas informasi berpengaruh terhadap kepuasan konsumen dalam berbelanja fashion online di Banda Aceh

2 Kemudahan transaksi berpengaruh terhadap loyalitas konsumen dalam berbelanja fashion online di Banda Aceh

3 Kualitas informasi berpengaruh terhadap loyalitas konsumen dalam berbelanja fashion online di Banda Aceh

4 Kemudahan transaksi berpengaruh terhadap loyalitas konsumen dalam berbelanja fashion online di Banda Aceh

5 Kepuasan Konsumen berpengaruh terhadap Loyalitas konsumen dalam berbelanja fashion online di Banda Aceh.

6 Kualitas informasi berpengaruh terhadap loyalitas konsumen melalui kepuasan konsumen dalam berbelanja fashion online di Banda Aceh.

7 Kemudahan transaksi berpengaruh terhadap loyalitas konsumen melalui kepuasan konsumen dalam berbelanja fashion online di Banda Aceh.

\section{Saran}

1 Untuk penelitian selanjutnya agar mengembangkan serta lebih banyak menggunakan variabel dan melibatkan banyak responden dalam melakukan penelitian sehingga dapat menghasilkan hasil yang lebih baik.

2 Untuk para pengguna jasa online shop adalah sebaiknya dengan menggunakan situs resmi yang terpercaya dan memilih kualitas barang yang tinggi ketika melakukan transaksi online shop. Online shop memberikan berbagai kemudahan dalam proses transaksinya oleh sebab itu disarankan kepada para pengguna jasa online shop harus lebih jeli memanfaatkan jasa tersebut dan memilih barang yang dapat digunakan secara fungsi barang tersebut

3 Email atau kuesioner online membutuhkan waktu yang lebih lama karena responden banyak yang malas membuka email, maka sebaiknya hanya menggunakan kuesioner yang disebar langsung.

\section{DAFTAR PUSTAKA}

Aaker, J.L. (2011), "Dimensions of Brand Personality," Journal of Marketing Research, Vol. 34 (August), pp. 70-80

Anderson, Eugene W., Claes Fornell \& Donald R. Lehmann (2011), "Customer Satisfaction, Market Share and Profitability : Finding From Sweden", Journal of Marketing, Vol. 58.

Arikunto, Suharsimi. 2011. Prosedur Penelitian Suatu Pendekatan. Praktek Edisi Revisi V. Jakarta: Rineka Cipta

A.Shimp, Terence., Periklanan Promosi dan Aspek Tambahan Komunikasi Pemasaran Edisi ke 5 Jilid 1. Jakarta : Penerbit Erlangga, 2010.

Baron, R.M. and Kenny, D.A. (1986). The moderator-mediator variable distinction in social psychological research: Conceptual, strategic, and statistical considerations. Journal of Personality and Social Psychology. 51(6): 11731182 .

Bei, Lien-Ti and Yu-Ching Chiao (2001). An integrated Model for Effects of PerceivedProduct, Perceived Service Quality, Perceived Price Fairness on Consumer Satisfaction and Loyalty. Journal of Consumer Satisfaction, Dissatisfaction and Complaining Behaviour, Provo.

Blanchette, M. C. 2001. A Chemical and Ecotoxilogical Assessment of the Impact of Marine Tailing and Mine Waste '01. Balkema, Rotterdam:323-331

Bodnar, George H. dan William S. Hopwood. 2009. Sistem Informasi Akuntansi, Edisi 9, Penerbit Andi, Yogyakarta. 
Chin, W.W. (1998), "The Partial Least Squares Approach for Structural Equation Modeling”, In Marcoulides, G.A. (Ed), Modern Method for Business Resaearch, Mahwah. NJ. Erlbaum Associates, hal. $295-358$.

Cronin, J.Joseph Jr dan Steven Taylor. (2013), Measuring Service Quality Reexamination and Extension, Journal of Marketing.

Cronin Jr, J. Josep, Michael K. Brady And G. Thomas M. Hult, 2000, Assessing The Effect Of Quality, Value And Customer Satisfaction On Cunsumer Behavioral Intentions In Service Environments, Journal Of Retailing, Vol. 76. No. 2, Pp. 193-218.

DeLone, W.H., dan McLean, E.R. (2010), "The DeLone and McLane of Information Systems Success: a ten - year update", Journal of Management Information Systems, Vol. 19, No. 4, hal. 9-30.

Davis B. Grodon. 2010. Kerangka Dasar Sistem Informasi Manajemen, alih bahasa Harwadi, LPPM dan PT. Pustaka Binaman, Pressindo, Jakarta.

Duffy, Jo Ann M. and Alice A. Ketchand, 2008, "An Examining The Role of Service Quality in Overall Service Satisfaction Online's Shop," Journal of Managerial Issues, Vol 10 No2

Eid, Mustafa I. 2011. Determinants Of ECommerce Customer Satisfaction, Trust, And Loyalty In Saudi Arabia, Journal of Marketing Research, Vol. 9, 1:79-83.

Evans, Joel R and Laskin, Richard L., 2004, The Relationship Marketing Process: AConceptualization and Application, Industrial Marketing Management 23.

Ferdinand, Augusty.2011.Structural Equation Modeling Dalam Penelitian Manajemen. Edisi ke-2.Semarang: BP UNDIP

Fornell, C., dan Larcker, D. (1981), "Evaluating Structural Equation Models with Unobservable Variable and Measurement Error", Journal of
Marketing Research, Vol. 18, hal. 39 50.

Gerson, Richard. F. 2010. Mengukur Kepuasan Pelanggan, PPM, Jakarta.

Gefen, David (2002),"Customer Loyalty in ECommerce,"Journal of the Association for Information Systems, Volume 3

Ghozali, Imam. 2006. Structural Equation Modeling Metode Alternatif dengan Partial Least Square. Semarang: Badan Penerbit UNDIP

Griffin, Jill (2011) Customer Loyalty: How to earn it, How to keep it, USA: A Division Of Simon and Schukers Inc.

Hair, J.F., et al. (2010). Multivariate data analysis. (7th edition). New Jersey :Pearson Education Inc.

Hennig-Thurau, Thorsten and Klee, Alexander, 2007, The Impact ofCustomer Satisfaction and Relationship Quality on Customer Retention: A Critical Reassesment and Model Development, Psychology andMarketing 14 (8).

Jia and Shen. (2004). User Acceptance of Social Shopping Situs : A Research Proposal, Pacific Asia Conference on Information Systems proceedings.

Jeon, Myunghee. 2009, Impact of perceived website service quality on customer e loyalty on a lodging website, Journal of Marketing Research, Paper 11068.

Junaidi, Shellyana dan B.S. Dharmmesta (2010), "Pengaruh Kepuasan Konsumen, Karakteristik Kategori Produk, dan Kebutuhan Mencari Variasi Terhadap 72 Keputusan Perpindahan Merek,” Jurnal Ekonomi dan Bisnis Indonesia, Vol. 17, No. 1, pp. 70-75.

Kim, Y.J., \& Xu, H.Y. (2004). The effect of justice and trust on eWOM in social media marketing: focused on power blog and meta blog. The Journal of Internet Electronic Commerce Research, Vol. 10, No. 3, pp. 131-155.

Kotler, Philip., and Keller K. L. 2013. Marketing Management. Pearson 
International Edition, Twelfth Edition. Singapore: Prentice Hall.

Kotler, Philip dan Kevin Lane Keller. (2012). Marketing Management Fourteenth Edition. New Jersey: Pearson Education.

Koufaris, Marios; Hampton-Sosa, William. 2002. "Customer Trust Online: Examining The Role of The Experience with The Website", CIS Working Paper Series.

Lee, C. S., 2001. An Analytical Framework for Evaluating E-Commerce Business Models and Strategies, Internet Research: Electronic NetworkingApplications and Policy, 11 (4): 349-359.

Lindestad, Andreassen. 2000. Saints and markets: Activists and the supply of credence goods. Journal of Economics \& ManagementStrategy, 10(1), 149-171.

Makeover, B 2003. Examining the employeecutomer chain in the fitness industry. Dissertation. Florida :The Florida State University, College of Education, pp. 1133

Morgan, R.M. and Hunt, S.D. (2005), “The commitment-trust theory of relationship marketing", Journal of Marketing, Vol. 64 No. 3, pp. 20-38.

Negash, S., Ryan, T., and Igbaria, M. 2009. Quality and Effectiveness in Web Based Customer Support Systems. Information \& Mangement, p175-180.

O'Brien, James A. 2011. Pengantar Sistem Informasi. Penerbit Salemba Empat, Jakarta

Oliver, Richard L., 2011, "Cognitive, Affective and Attribute Base of the Satisfaction Response", journal of consumer research, p.87-91.

Ong, C.S., Day, M.Y., and Hsu, W.L. 2010. A Measurement of User Satisfaction with Question Answering Systems. Information and Management, p 397400.
Patterson, Paul G. and Richard A. Spreng (2009), "Modeling the Relationship between Perceived Value, Satisfaction, and Repurchase Intentions in a Businessto-Business, Services Context: An Empirical Examination," International Journal of Service Industry Management, p 70-76.

Peter, J. Paul dan Olson, Jerry C.(2009). Perilaku Konsumen dan Strategi Pemasaran, Alih bahasa Damos Sihombing, Penerbit Erlangga, Jakarta, hal. 44-50.

Petruzzellis, L., D’Uggento, A.M., dan Romanazzi, S. (2009), "Student satisfaction and quality of service in Italian universities", Managing ServiceQuality: An International Journal, Vol. 16 No. 4, pp. 349-364.

Ramayah and Joshua Ignatius, 2013, Impact of Perceived usefulness, Perceived ease of use and Perceived Enjoyment on Intention to shop online, Journal of Marketing, 131-141.

Ryan, M.J., Rayner, R., \& Morris, A., 2000, "Diagnosing Customer Loyalty Drivers", Marketing Research, Summer

Santos, Cristiane and Daniel Fernandes. 2011. Perceptions of Justice after Recovery Efforts in Internet Purchasing: the Impact on Consumer Trust and Loyalty toward Retailing Sites and Online Shopping in General, Journal of Marketing, pp. 225-246.

Schaupp and Bélanger (2005). "A Conjoint Analysis of Online Consumer Satisfaction," Journal of Electronic Commerce Research, Vol. 6, No.2, pp. 95-111.

Schmidt, J.R. dan Sapsford, M.E, (2005), Operations Management Customer Fokused Principles, Sixth Edition, IRWIN, Chicago.

Schnaars, Steven P. (2012). Marketing Strategy : A customer Driven Approach.2nd ed. New York: The Free Press. 
Sekaran, U. 2012. Research Methods for Business : A Skill Building Approach 2nd Edition, John Wiley and Son. New York.

Simona. 2013, The Impact of Customer Perceptions and Satisfaction on ELoyalty, Journal of Marketing, Vol. 4 16.

Smith, S.M. and Albaum, G.S. 2010.Measuring RespondentInformation:

Attitudes,Satisfaction, Loyalty, andBehavior. An Introduction toMarketing Research.

Sugiyono. 2010. Statistika Untuk Penelitian. Bandung: CV. Alfabeta

Teas, R. Kenneth. 2013, "Expectations, Performance,Evaluation, and Consumers' Perceptions of Quality", Journal of Marketing, Vol. 57, October, p.70-80.
Van riel Allard C.R. et al, (2004).”Online Travel Service Quality Toward Delighted And Loyal", Total Quality Management. Vol 15. No.4, 475-493.

Wen, Chao; Prybutok, Victor.R dan Xu, Chenyan 2011. "An Integrated Model for Customer Online Repurchase Intention". 2011. Journal of Computer Information Systems.

www.survey APJJI , 5 April 2014

Zeithaml, Valarie \& Mario Jo Bitner , 2006, Service Marketing, New York, Mc Graw Hill Companies Inc. 